\title{
A STUDY ON KNOWLEDGE MANAGEMENT CAPABILITIES TOWARDS NEW PRODUCT INNOVATION TYPE AND DEVELOPMENT PERFORMANCE OF CHINESE BUSINESSES
}

\author{
Sheng XU \\ College of Finance / school of MBA, Zhongnan University of Economics and Law, Hubei 430073, \\ China. \\ E-mail:bzhiwsmd@163.com
}

\begin{abstract}
A business needs to constantly innovate and reinforce the competitiveness for the survival development and sustainable management. Focus on new product development has become the key factor in modern manufacturers maintaining the competitiveness. The process and the results depend on the effective application and management of organizational knowledge that it is necessary to reinforce the capabilities in order to promote the new product development performance.

With random sampling, the employees and the managers in top ten businesses of 1,000 Chinese industrial businesses are distributed 1,000 copies of questionnaire. Total 568 effective copies are retrieved, with the retrieval rate $57 \%$. The results show 1 . the significantly positive correlation between knowledge acquisition capabilities in knowledge management capabilities and new product development performance, 2 . the remarkably positive correlation between knowledge transformation and application capabilities in knowledge management capabilities and new product development performance, 3 . the notably positive correlation between knowledge protection capabilities in knowledge management capabilities and new product development performance, and 4 . the significant moderating effects of product innovation type on the correlation between knowledge management capabilities and new product development performance. The research results are expected to provide essential contributions and suggestions for the knowledge management capabilities and the new product development of Chinese businesses.
\end{abstract}

Keywords: Chinese business, knowledge management capabilities, new product innovation type, new product development performance 


\section{RESEARCH MOTIVATION AND BACKGROUND}

Under the fiercely competitive environment, a business has to constantly innovate and reinforce the competitiveness for the survival development and sustainable management. The promotion of new products is the specific performance of a business innovation that the new product development becomes the key of a business investing in resources. Business performance directly relates to the success in new product development and highly contributes to the business revenue. Aboelmaged (2012) pointed out the continuous promotion of new products and satisfaction with customer demands as the key indices in the growth and success of a business. Dibrell et al. (2011) indicated that the new product development was likely affected by the environment, which was considered as the key in business prosperity. The success of new products not only brings more profits, but also enhances the value and status of a business in the market. Each stage of new product development involves in the application of knowledge; from the generation of product ideas to the release, the collection of market news, the cross-sectional technical exchange and integration, and the share of common organizational database are closely related to the knowledge management capabilities of a business. Knowledge management capabilities therefore have become a key factor in an organization enhancing the competitiveness and creating value. For instance, an organization could effectively spread and exchange various types of knowledge from different sources in the organization, through the transformation of knowledge management, for the use of employees for distinct tasks and purposes. Accordingly, it is an essential trend for a business cultivating the knowledge management capabilities. Even so, a business still needs to deliberately consider the external interference when investing and cultivating relevant knowledge management capabilities for further acceptance or rejection aiming at the knowledge management capabilities in the process. A business hastily investing too many resources or executing over conservatively would affect the development of knowledge management capabilities as well as drag down the overall performance. For this reason, this study aims to investigate knowledge management capabilities towards new product innovation type and development performance of Chinese businesses. 


\section{LITERATURE REVIEW}

\subsection{Knowledge management capabilities}

Bolívar-Ramos et al. (2012) regarded knowledge management as the process to practice organizational objectives and further indicated that knowledge management could present organizational design and was the aggregation of operation principles and process application techniques to create value for the business. Hsiao and Chang (2011) considered that the knowledge architecture was composed of technology, structure, and culture with knowledge acquisition, transformation \& application, and protection; it was the meaning of knowledge management. Mirkamali et al. (2011) pointed out knowledge as the asset of knowledge management capabilities, including the inventory, evaluation, monitoring, regulation, acquisition, learning, distribution, protection, and innovation of knowledge to enhance knowledge assets. Robbins (2013) regarded knowledge management capabilities as the process of acquiring and sharing intellectual assets and being able to enhance useful and circular information in an organization as well as to promote individual and group learning (DuBrin 2012). In the research on product development, Lai and Lin (2012) divided knowledge management capabilities into four processes, including (1) knowledge creation, the acquisition and exploration of knowledge creation as mentioned in past literatures, (2) knowledge application, (3) knowledge integration, covering knowledge transfer, distribution, and transformation, and (4) knowledge conservation, containing protection and maintenance. Khattak et al. (2013) proposed knowledge management capabilities of knowledge acquisition, knowledge transformation \& application, and knowledge protection. When a business completed the acquisition and transformation processes, the knowledge management capabilities were established. The establishment of retrieval capabilities therefore allowed an organization rapidly accessing and applying knowledge resources to assist the business in interpreting and explaining problems and creating knowledge and decisions to promote the competitive advantage.

From the viewpoint of organization capabilities, DuBrin (2012) classified knowledge management capabilities into knowledge acquisition capabilities, knowledge transformation and application capabilities, and knowledge protection capabilities. Such three knowledge management capabilities cover the above research variables that they are utilized for measuring knowledge management capabilities in this study.

1. Knowledge acquisition capabilities. Acquisition-oriented knowledge management capabilities refer to acquisition, search, generation, creation, and co- 
operation. Such terms present the accumulation of knowledge. 2. Knowledge transformation and application capabilities. It is a process allowing current knowledge presenting the function. The process of knowledge transformation capabilities refers to the capabilities of organizing, integrating, combining, coordinating, and spreading knowledge. 3. Knowledge protection capabilities. Security-oriented knowledge management process is designed to protect knowledge in an organization from being illegally or improperly used and stolen (Wang and Ellinger 2011).

\subsection{Product innovation type}

Al-Adaileh and Al-Atawi (2011) pointed out innovation as a new method producing or manufacturing new products in a business, containing the increase of product patterns and the management system, organization structure, and strategy development in the production process. Franke and Felfe (2012) further defined innovation as the application of new knowledge, which contained technical and market knowledge, to provide customers with required new products or services. Innovation was regarded as the combination of invention and commercialization that anything which could not satisfy customer demands and bring profits could not be innovation. Hung et al. (2011) defined product innovation according to the novelty of new products towards the company and the market. The novelty towards a company referred to the production or sales of other companies while the company did not have such experience. The novelty towards the market generally referred to the first released product innovation. Such two dimensions were further classified into six categories.

(1) New product: a product to create a brand-new market. (2) New product line: new products allowing a company entering the current market for the first time. (3) Increase of items on current product line: New products to increase current product lines of a company, under the existing product production capabilities. (4) Improvement or update of existing products: New products which could provide improvement or larger cognitive value and replace current products. (5) Repositioning: having existing products enter a new market or segmentation. (6) Cost reduction: redesigning products with same functions but lower costs. Napora (2011) proposed technical novelty and market novelty and classified new product and service innovation into discontinuous innovation and incremental innovation. Based on distinct research objectives, the measurement of product innovation type was different, but the meaning was similar. For example, both discontinuous innovation and radical innovation referred to the great innovation 
of new products towards current products (Rodríguez-Pinto et al. 2011); similarly, incremental innovation, evolutional innovation, and continuous innovation indicated to improve, modify, or reorientate original products. The product innovation type is divided into radical innovation and incremental innovation in this study.

\subsection{New product development performance}

Analoui et al. (2012) defined new products as "new products for a company", including unprecedented products, quality, and package modification, imitating existing products of competitors, introducing foreign products for the first time, and adding "new" ideas to all product composition. New products were those most customers in a certain market considered as "new". Dibrell et al. (2011) defined new products as the products being able to satisfy customer demands or consuming systems; it also represented a more efficient tactic to solve customer problems. García-Morales et al. (2012) defined new products as a product which a business did not have before, regardless whether there was such a product in the market. For certain products, businesses, or countries, Analoui et al. (2012) indicated that either a globally new product or the improvement of an existing product could be regarded as a new product. Jiménez-Jiménez and Sanz-Valle (2011) considered new products as new things for a business, market, or industry, which could profit the customers.

Nguyen and Mohamed (2011) measured new product development performance with the dimensions of (1) new product development budget and schedule conforming to the original plan, (2) new product development conforming to the function, specification, reliability, and maintenance standard set for new products, and (3) the degree of success subjectively setting the entire plan. Tohidi and Jabbari (2012) pointed out four dimensions to measure new product development performance, including (1) the sales lower than exceeding or maintaining the target standard, (2) the achievement of the market share target, (3) the new product profitability, and (4) the overall satisfaction with the new product development. In the research on the effects of learning styles and market-oriented fit on new product development performance, Yang and Lai (2012) proposed the following dimensions to measure new product development performance, namely (1) relative sales volume, (2) relative market share, (3) relative profitability, and (4) relative return on investment. 


\subsection{Hypothesis deduction}

In the investigation of dynamic capabilities for an organization developing new products in order to enhance the performance, Becan et al. (2012) considered that new product development was originated from the application of organizational knowledge that organizational capabilities were divided into knowledge creation capabilities, knowledge integration capabilities, and knowledge reorganization capabilities. It was also discovered that knowledge creation capabilities and product innovation type could positively affect new product development performance. Conner and Rabovsky (2011) regarded knowledge management capabilities as a key factor in organizational innovation and discovered the same opinions of several researchers in the literature review. Based on the dimensions for knowledge management capabilities proposed by Tohidi and Jabbari (2012), hypothesis research was further proceeded to verify the relationship between knowledge acquisition, knowledge transformation, knowledge application in knowledge management and organizational innovation. The results proved the positive effects of knowledge management capabilities on new product development performance, and knowledge application appeared the largest effect. Khattak et al. (2013) pointed out the critical role of knowledge acquisition in product innovation type; an organization could acquire knowledge which an organization lacked and required through strategic partners to enhance the new product development performance. A German company was further studied to prove the positive effects of knowledge management capabilities on new product development performance.

Accordingly, the following hypotheses are proposed in this study.

H1. Knowledge acquisition capabilities in knowledge management capabilities present significantly positive correlation with new product development performance.

H2. Knowledge transformation and application capabilities in knowledge management capabilities reveal remarkably positive correlation with new product development performance.

H3. Knowledge protection capabilities in knowledge management capabilities show notably positive correlation with new product development performance.

Based on resources, Lai and Lin (2012) investigated new product development and indicated that current database in an organization could no longer cope with high-innovation product development; an organization should stress on knowledge integration and translation to reach the product innovation by the good use of organizational members. After studying 90 new product development projects, Randall et al. (2011) discovered that an organization being able to effectively share and utilize knowledge in the radical innovation would enhance the product 
development performance. Continuously communicating and exchanging crossfunctional and cross-national information to share, integrate, and apply individual knowledge could enhance the new product development performance. In the research on new product development process being interfered by environmental uncertain factors, Yang and Lai (2012) investigated 224 manufacturers in Korea and found out the moderating effects of product innovation type on knowledge management integration and new product development performance.

From the above literatures, the following hypothesis is also proposed in this study.

H4. Product innovation type has significant moderating effects on the correlation between knowledge management capabilities and new product development performance.

\section{RESEARCH METHODOLOGY}

\subsection{Research architecture}

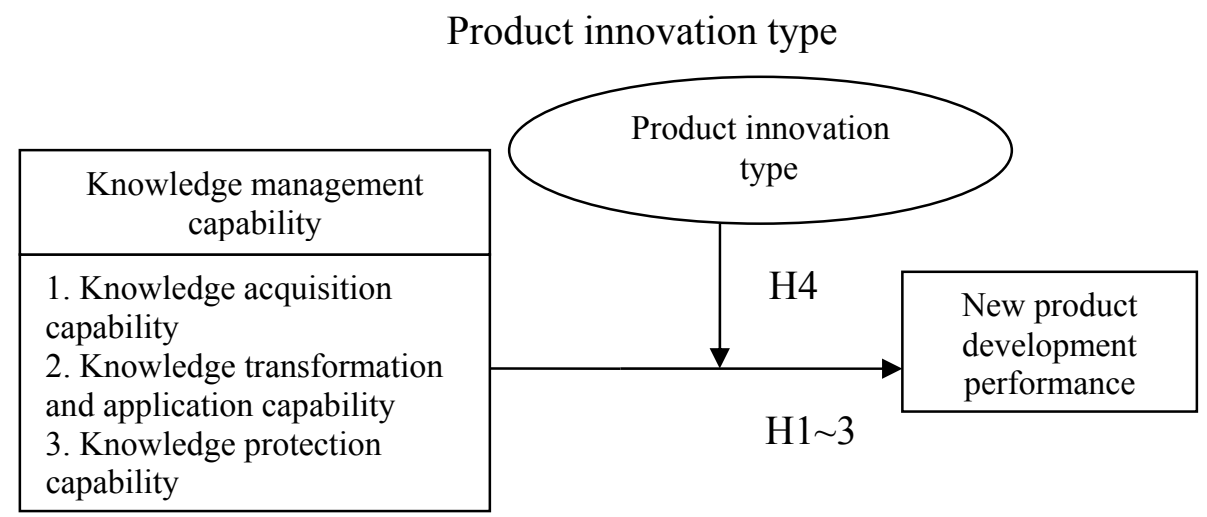

Research architecture I

\subsection{Research sample}

Aiming at top ten businesses in 1,000 Chinese industrial businesses, including Daqing Oilfifld of CNPC, State Grid Jiangsu Electric Power Company, Hong Fu Jin Precision Industry (Shenzhen) Co., Ltd., China First Automobile Group Corporation, Shanghai Volkswagen, FAW-Volkswagen Automotive Co. Ltd., Tech- 
Front (Shanghai) Computer Co., Ltd., Baoshan Iron \& Steel Co., Ltd., China Petroleum \& Chemical Corporation, Shengli Oilfield Branch, and State Grid Zhejiang Electric Power Company, the employees and managers are randomly sampled for the e-questionnaire survey. Total 1,000 copies of questionnaire are distributed, and 579 copies are retrieved, in which 568 copies are valid, with the retrieval rate $74 \%$.

\subsection{Research instrument}

(1) Knowledge management capability scale

Referring to DuBrin (2012), the knowledge management capability scale, through Factor Analysis, is extracted three factors with the eigenvalue larger than 1; the factor load of the questions appears in $0.73 \sim 0.88$ and the composite reliability in $0.86 \sim 0.92$. The three factors are knowledge acquisition capabilities, knowledge transformation and application capabilities, and knowledge protection capabilities, and the accumulated covariance explained reaches $78.533 \%$.

(2) New product development performance scale

Referring to Analoui et al. (2012), the new product development performance scale, through Factor Analysis, is extracted a factor with the eigenvalue larger than 1 . The factor load shows 0.84 and the factor composite reliability 0.87 . The accumulated covariance explained achieves $83.627 \%$.

(3) Product innovation type scale

Referring to Napora (2011), the product innovation type scale, through Factor Analysis, is extracted two factors with the eigenvalue larger than 1 . The factor load is in $0.82 \sim 0.86$ and the factor composite reliability in $0.80 \sim 0.83$. The two factors are Radical Innovation and Incremental Innovation, and the accumulated covariance explained reaches $91.716 \%$.

From the above analysis results, knowledge management capabilities, new product development performance, and product innovation type present proper reliability. Furthermore, the factors extracted from knowledge management capabilities, new product development performance, and product innovation type are consistent with the operational definitions in this study that the scales reveal proper construct validity. 


\section{RESULT AND ANALYSIS}

\subsection{Variable correlation analysis}

The multicollinearity does not appear among the research variables, according to the correlation coefficient among knowledge management capabilities, new product development performance, and product innovation type, see Table 1. In this case, the sample data are suitable for regression analysis.

Table 1. Correlation analysis

\begin{tabular}{|l|c|c|c|c|c|c|}
\hline Variable & 1 & 2 & 3 & 4 & 5 & 6 \\
\hline Knowledge acquisition capabilities & 0.02 & & & & & \\
\hline $\begin{array}{l}\text { Knowledge transformation and applica- } \\
\text { tion capabilities }\end{array}$ & 0.04 & & & & & \\
\hline Knowledge protection capabilities & -0.02 & 0.07 & & & & \\
\hline Radical innovation & 0.16 & $0.21^{*}$ & $0.23^{*}$ & & & \\
\hline Incremental innovation & $0.25^{*}$ & $0.29^{*}$ & $0.31^{*}$ & 0.05 & & \\
\hline New product development performance & $0.27^{*}$ & $0.24^{*}$ & $0.22^{*}$ & -0.11 & -0.08 & \\
\hline
\end{tabular}

\subsection{Relationship among knowledge management capabilities, product innovation type, and new product development performance}

In regard to multiple regression analysis of knowledge management and organization performance, knowledge acquisition capabilities, knowledge transformation and application capabilities, and knowledge protection capabilities in knowledge management capabilities are regarded as the independent variables, and new product development performance as the dependent variable. The analysis results are organized in Table 2. The results show the notably positive correlation between knowledge acquisition capabilities, knowledge transformation and application capabilities, knowledge protection capabilities, knowledge acquisition capabilities in knowledge management capabilities and new product development performance. $\mathrm{H} 1$ therefore is supported. Knowledge transformation and application capabilities in knowledge management capabilities reveal remarkably positive correlation with new product development performance that $\mathrm{H} 2$ is supported. Knowledge protection capabilities in knowledge management capabilities have significantly positive correlation with new product development performance that $\mathrm{H} 3$ is supported.

From Table 2, knowledge acquisition capabilities, knowledge transformation and application capabilities, and knowledge protection capabilities show remarkably positive effects $\left(\beta=0.183^{*} \sim 0.204^{* *}, \beta=0.208^{* *} \sim 0.257^{* * *}\right.$, 
$\left.\beta=0.173^{*} \sim 0.226^{* *}\right)$, with increasing strength, on new product development performance under the moderating effects of product innovation type being input and the moderating effect of product innovation type. Such a result conforms to the prediction that $\mathrm{H} 4$ is supported.

Table 2. Hierarchical regression analysis

\begin{tabular}{|c|c|c|c|c|}
\hline \multirow[t]{3}{*}{ Hierarchical variable } & \multirow{3}{*}{$\begin{array}{l}\text { Predicted variable } \\
\text { in hierarchy }\end{array}$} & \multicolumn{3}{|c|}{ New product development performance } \\
\hline & & Hierarchy I & Hierarchy II & Hierarchy III \\
\hline & & $\beta$ & $\beta$ & $\beta$ \\
\hline \multirow{3}{*}{$\begin{array}{l}\text { Knowledge } \\
\text { management } \\
\text { capabilities }\end{array}$} & $\begin{array}{l}\text { Knowledge acquisition } \\
\text { capabilities }\end{array}$ & $0.183^{*}$ & $0.197 *$ & $0.204 * *$ \\
\hline & $\begin{array}{l}\text { Knowledge transformation } \\
\text { and application capabilities }\end{array}$ & $0.208 * *$ & $0.232 * *$ & $0.257 * * *$ \\
\hline & $\begin{array}{l}\text { Knowledge protection } \\
\text { capabilities }\end{array}$ & $0.173^{*}$ & $0.191^{*}$ & $0.226^{* *}$ \\
\hline \multirow{2}{*}{$\begin{array}{l}\text { Product innovation } \\
\text { type }\end{array}$} & Radical innovation & & 0.106 & 0.083 \\
\hline & Incremental innovation & & $0.215 * *$ & $0.233 * *$ \\
\hline \multirow[t]{6}{*}{ Interactive terms } & $\begin{array}{l}\text { Knowledge acquisition } \\
\text { capabilities } \times \text { radical } \\
\text { innovation } \\
\end{array}$ & & & $0.168^{*}$ \\
\hline & $\begin{array}{l}\text { Knowledge transformation } \\
\text { and application capabilities } \\
\times \text { radical innovation } \\
\end{array}$ & & & $0.173^{*}$ \\
\hline & $\begin{array}{l}\text { Knowledge protection } \\
\text { capabilities } \times \text { radical } \\
\text { innovation } \\
\end{array}$ & & & -0.147 \\
\hline & $\begin{array}{l}\text { Knowledge acquisition } \\
\text { capabilities } \times \text { incremental } \\
\text { innovation }\end{array}$ & & & 0.124 \\
\hline & $\begin{array}{l}\text { Knowledge transformation } \\
\text { and application capabilities } \\
\times \text { incremental innovation } \\
\end{array}$ & & & $0.157^{*}$ \\
\hline & $\begin{array}{l}\text { Knowledge protection } \\
\text { capabilities } \times \text { incremental } \\
\text { innovation }\end{array}$ & & & $0.209 * *$ \\
\hline \multirow{4}{*}{$\begin{array}{l}\text { Abstract of regression } \\
\text { model }\end{array}$} & $\mathrm{F}$ & 8.155 & 11.732 & 26.316 \\
\hline & \begin{tabular}{|l|} 
Significance \\
\end{tabular} & $0.000 * * *$ & $0.000 * * *$ & $0.000 * * *$ \\
\hline & $\mathrm{R}^{2}$ & 0.157 & 0.195 & 0.278 \\
\hline & $\Delta \mathrm{R}^{2}$ & 0.157 & 0.038 & 0.083 \\
\hline
\end{tabular}

$* \mathrm{p}<0.05, * * \mathrm{p}<0.01, * * * \mathrm{p}<0.001$ 


\section{CONCLUSION}

The empirical analysis results show the notably positive correlation between knowledge management capabilities and new product development performance in Chinese businesses, meaning the higher knowledge management capabilities of a Chinese business would better present new product development performance. Knowledge transformation and application capabilities and knowledge protection capabilities in incremental innovation would enhance the new product development performance of a Chinese business. However, incremental innovation often refers to low-level innovation of product improvement or efficiency promotion; collecting market and technical information to understand customer demands and competitor movement therefore become the primary issue for incremental innovation. In radical innovation, knowledge acquisition capabilities and knowledge transformation and application capabilities would enhance the new product development performance of a Chinese business. Radical innovation involves in high-level innovation that a Chinese business has to get rid of the existing knowledge and technical structure and generate the product model different from the past; therefore, the capabilities of knowledge use would become more important. A Chinese business has the organization knowledge become transparent and easy to use by cross-sectional communication and exchange and sharing knowledge for mutual learning to propose opinions and ideas for radical innovation. Overall speaking, a Chinese business with incremental innovation and stressing on knowledge protection capabilities would present better new product development performance.

\section{SUGGESTION}

According to the research results, the following suggestions are proposed in this study.

1. A Chinese business could enhance the new product development performance by reinforcing the knowledge acquisition capabilities and understanding the customer demands. It could continuously acquire various external knowledges, establish professional departments to collect market information and feedback, enhance the closeness with customers in order to understand the target customers' demands, and cooperate with relevant manufacturers to acquire insufficient knowledge.

2. When a Chinese business intends to promote the new product development performance by enhancing the knowledge transformation and application capabilities, it has to reinforce the integration and circulation of internal 
knowledge, such as proceeding internal cross-sectional and cross-level technical discussions, case sharing, or improving the knowledge management information system so that the employees could conveniently store and access to proper knowledge. In sum, a Chinese business should develop proper knowledge management capabilities by considering the objectives and external environments.

3. A Chinese business would reinforce the knowledge protection capabilities when executing works related to knowledge management capabilities. In regard to knowledge protection, a Chinese business has to treat the possessed knowledge as precious assets and protect organizational confidential knowledge through the establishment of internal knowledge management systems and the establishment of systems, regulations, and patents.

\section{ACKNOWLEDGEMENTS}

The fundamental funds (2014) for Zhongnan University of Economics and Law; "The national social science fund of China" (09CJL025).

\section{REFERENCES}

Aboelmaged, M.G. (2012). Harvesting organizational knowledge and innovation practices: An empirical examination of their effects on operations strategy. Business Process Management Journal, 18(5), 712-734.

Al-Adaileh, R.M. and Al-Atawi, M.S. (2011). Organizational culture impact on knowledge exchange: Saudi Telecom context. Journal of Knowledge Management, 15(2), 212-230.

Analoui, B.D., Doloriert, C.H. and Sambrook, S. (2012). Leadership and knowledge management in UK ICT organisations. Journal of Management Development, 32(1), 4-17.

Becan, J.E., Knight, D.K. and Flynn, P.M. (2012). Innovation adoption as facilitated by a changeoriented workplace. Journal of Substance Abuse Treatment, 42(2), 179-190.

Bolívar-Ramos, M.T., García-Morales, V.J. and García-Sánchez, E. (2012). Technological distinctive competencies and organizational learning: Effects on organizational innovation to improve firm performance. Journal of Engineering and Technology Management, 29(3), 331-357.

Conner, T.W. and Rabovsky, T.M. (2011). Accountability, affordability, access. A review of the recent trends in higher education policy research. The Policy Studies Journal, 39 (1), 93-112.

Dibrell, C., Craig, J.B. and Hans, E.N. (2011). How managerial attitudes toward the natural environment affect market orientation and innovation. Journal of Business Research, 64(4), 401-407.

Dibrell, C., Craig, J.B. and Hansen, E.N. (2011). How managerial attitudes toward the natural environment affect market orientation and innovation. Journal of Business Research, 64(4), 401-407.

DuBrin, A.J. (2012). Leadership: Research Findings, Practice, and Skills. South-Western Publ.

Franke, F. and Felfe, J. (2012). Transfer of leadership skills. Journal of Personnel Psychology, $11(3), 138-147$. 
García-Morales, V.J., Jiménez-Barrionuevo, M.M. and Gutiérrez-Gutiérrez, L. (2012). Transformational leadership influence on organizational performance through organizational learning and innovation. Journal of Business Research. 65(7), 1040-1050.

Hsiao, H.C. and Chang, J.C. (2011). The role of organizational learning in transformational leadership and organizational innovation. Asia Pacific Education Review, 12(4), 621-631.

Hung, R.Y.Y., Lien, B.Y-H., Yang, B., Wu, C-M. and Kuo, Y-M. (2011). Impact of TQM and organizational learning on innovation performance in the high-tech industry. International Business Review, 20(2), 213-225.

Jiménez-Jiménez, D. and Sanz-Valle, R. (2011). Innovation, organizational learning, and performance. Journal of Business Research, 64(4), 408-417.

Khattak, M.A., Iqbal, N. and Khattak, S. R. (2013). Constructive relationship between Employee's adaptability and performance builds up new trends and practices in Pakistani organizations.

Lai, Y.L. and Lin, F.J. (2012). The effects of knowledge management and technology innovation on new product development performance. An empirical study of Taiwanese machine tools industry. Procedia - Social and Behavioral Sciences, 40, 157-164.

Mirkamali, S.M., Thani, F.N. and Alami, F. (2011). Examining the role of transformational leadership and job satisfaction in the organizational learning of an automotive manufacturing company. Procedia - Social and Behavioral Sciences, 29, 139-148.

Napora, L. (2011). Mediation in higher education: The question of change. A current problem, and evidence toward a solution. Biofeedback, 39(2), 64-66.

Nguyen, H.N. and Mohamed, S. (2011). Leadership behaviors, organizational culture and knowledge management practices: An empirical investigation. Journal of Management Development, 30(2), 206-221.

Randall, K.R., Resick, C.J. and DeChurch, L.A. (2011). Building team adaptive capacity: The roles of sensegiving and team composition. Journal of Applied Psychology, 96(3), 525-540.

Robbins, S. P. (2013). Organizational Behavior (15th ed.). Boston: Pearson.

Rodríguez-Pinto, J., Carbonell, P. and Rodríguez-Escudero, A.I. (2011). Speed or quality? How the order of market entry influences the relationship between market orientation and new product performance. International Journal of Research in Marketing, 28 (2) 145-154.

Tohidi, H. and Jabbari, M.M. (2012). Measuring organizational learning capability. Procedia Social and Behavioral Sciences, 31 (2012), 428-432.

Wang, Y-L. and Ellinger, A.D. (2011). Organizational learning: Perception of external environment and innovation performance. International Journal of Manpower, 32(5/6), 512-536.

Yang, C.H. and Lai, C.S. (2012). Relationship learning from organizational knowledge stores. Journal of Business Research, 65(2012), 421-428. 